\title{
Disruption of Prepulse Inhibition of Startle Reflex in a Neurodevelopmental Model of Schizophrenia: Reversal by Clozapine, Olanzapine and Risperidone But Not by Haloperidol
}

Gwenaëlle Le Pen, Ph.D., and Jean-Luc Moreau, Ph.D.

Neonatal ventral hippocampal (NVH) lesions in rats have been shown to induce behavioral abnormalities at adulthood thought to simulate some aspects of positive, negative and cognitive deficits classically observed in schizophrenic patients. Such lesions induced a postpubertal emergence of prepulse inhibition deficits reminiscent of the sensorimotor gating deficits observed in a large majority of schizophrenic patients. Here we have investigated the capacity of typical and atypical antipsychotics to reverse PPI deficits seen in $\mathrm{NVH}$ lesioned rats.
We show that three atypical antipsychotics (clozapine, olanzapine and risperidone) were able to reverse lesion-induced PPI deficits, in contrast to haloperidol, a classical neuroleptic.

These results show that the NVH lesion model seems to be endowed with a fair predictive validity as, like in schizophrenic patients, PPI deficits in lesioned animals were reversed by atypical antipsychotics but not by the typical neuroleptic haloperidol.

[Neuropsychopharmacology 27:1-11, 2002]

(C) 2002 American College of Neuropsychopharmacology. Published by Elsevier Science Inc.
KEY WORDS: Schizophrenia; Neonatal lesion; Hippocampus; Prepulse inhibition; Antipsychotics; Animal model

Schizophrenia has long been associated with abnormalities in information processing and attention mechanisms (Braff 1993; Nuechterlein et al. 1994; Perry and Braff 1994; Swerdlow and Geyer 1998). In an attempt to

From the Pharma Division, Preclinical CNS Research, F-Hoffmann-La Roche Ltd, CH-4070 Basel, Switzerland.

Address correspondence to: Dr. Jean-Luc Moreau, Pharma Division, Preclinical CNS Research, F-Hoffmann-La Roche Ltd, PRBN-B 72/141 CH-4070 Basel, Switzerland. Tel.: +(41) 61688 6951, Fax: +(41) 61688 1895, E-mail: jean-luc.moreau@roche.com

Received May 17, 2001; revised August 30, 2001; accepted September 28, 2001.

Online publication: 10/01/01 at www.acnp.org/citations/ Npp100101180. better understand mechanisms underlying the physiopathology of schizophrenia, sensorimotor information gating processes have received much attention. One well-established method for evaluating sensory filtering is the paradigm of prepulse inhibition (PPI) which refers to the inhibition of a startle reflex by presentation of a weak intensity prepulse immediately before the startle stimulus. Interestingly, PPI is an unlearned phenomenon using virtually identical techniques and parameters across species and it shows similar sensitivity to stimulus parameters in rats and human beings (Swerdlow et al. 1994). Disruption of PPI in schizophrenic patients has been well described in several studies (Braff et al. 1978, 1992; Bolino et al. 1994; Perry and Braff 1994). PPI deficits can also be observed in rats treated with psychotomimetic agents. Indeed, dopamine (DA) agonists such as apomorphine or amphet- 
amine and glutamate (GLU) antagonists induce disruption of PPI. DA agonist-induced PPI deficits are reversed by both typical and atypical antipsychotics whereas those induced by GLU antagonists seem to be reversed only by atypical antipsychotics (Swerdlow and Geyer 1993; Bakshi et al. 1994; Bakshi and Geyer 1995; Varty and Higgins 1995). As a model of schizophrenia, drug-induced PPI deficits in animals exhibit some degree of face, construct, and predictive validity (Ellenbroek and Cools 1990; Swerdlow et al. 1994) and are commonly used to try to identify effective therapies against schizophrenia.

An animal model of an illness is by definition a simplified version of the real condition created to study mechanisms of the disease and to develop effective therapies. The search for new non-pharmacological models which would also exhibit a fair degree of validity to several aspects of schizophrenia is essential. Recently, new such models have appeared, based on the neurodevelopmental hypothesis of schizophrenia which suggests that an abnormal development of the brain connectivity could be one of the mechanisms implicated in the genesis of schizophrenia (Weinberger 1986; Ellenbroek and Cools 1998; Duncan et al. 1999). Among these new models, long-term consequences of neonatal ventral hippocampal (NVH) lesions in the rat have been proposed by Lipska and co-workers as offering a valid simulation of psychotic disorders (Lipska et al. 1993; Lipska and Weinberger 1993, 2000). Indeed, NVH lesions in rats have been shown to induce post-pubertal emergence of behavioral abnormalities thought to simulate some aspects of positive, negative and cognitive symptoms classically observed in schizophrenic patients, such as hyperresponsiveness to stress, novelty, dopamine agonists or glutamate antagonists (Lipska et al. 1993, 1995a; Flores et al. 1996; Black et al. 1998; Brake et al. 1999; Al-Amin et al. 2000, 2001). These post-pubertal anomalies are reminiscent of the classically-described post-pubertal onset of psychotic symptoms in the majority of schizophrenic patients. Indeed, the onset of schizophrenia is frequently precipitated by a stressful event (Duncan et al. 1999), and psychological stress (Duncan et al. 1999) as well as dopamine agonists (Angrist and Van Kammen 1984; Lieberman et al. 1987) and glutamate antagonists (Meador-Woodruff and Healy 2000) are well documented to precipitate or exacerbate psychotic symptoms in humans. NVH-lesioned rats also exhibit deficits in social behavior (Sams-Dodd et al. 1997; Becker et al. 1999), in reward sensitivity (personal observations), in spatial and associative learning and working memory (Chambers et al. 1996; Le Pen et al. 2000) and in social memory (Becker and Grecksch 2000). Finally, NVH lesions induce a reliable postpubertal emergence of PPI deficits (Lipska et al. 1995b; Le Pen et al. 2000).
If the ability of this model to mimic some aspects of the schizophrenia symptomatology starts to be well established, relatively few studies have investigated its predictive validity by testing the capacity of antipsychotics to reverse abnormal behaviors induced by $\mathrm{NVH}$ lesions. It has only been shown that haloperidol and clozapine are effective in suppressing hyperlocomotion induced by NVH lesions (Lipska and Weinberger 1994), and social memory impairments were partly ameliorated by a subchronic treatment with haloperidol (Becker and Grecksch 2000). Finally, Sams-Dodd et al. have shown that chronic administration of clozapine had no effect on social behavior deficits observed in NVH-lesioned rats (Sams-Dodd et al. 1997) whereas recently Becker and coll. have shown the contrary (Becker et al. 2000).

Thus, this study was undertaken to evaluate the capacity of haloperidol (a typical antipsychotic), clozapine, olanzapine and risperidone (atypical antipsychotics) to reverse deficits of prepulse inhibition of startle reflex observed in $\mathrm{NVH}$-lesioned rats.

\section{MATERIALS AND METHODS}

\section{Surgery}

Sprague-Dawley rats (BRL, Füllinsdorf, Switzerland) were obtained at 3-4 days of age as whole litters together with their mother. They were kept on a 12-h light/12-h dark cycle (On: 6 A.M., Off: 6 P.M.) and fed ad libitum. All experimental procedures and protocols were approved by the local animal protection authorities. On the seventh day of age and at a body weight of 15 to $20 \mathrm{~g}$, male pups within each litter were randomized to Sham or Lesion status, anaesthetized by isoflurane inhalation ( $4 \%$ for induction and $1.5-3 \%$ for maintenance) through a mask, mounted on a stereotaxic Kopf instrument with an adapter for small animals (Harvard Biosciences) and additionally taped on a heating pad placed on the platform. The skin overlying the skull was incised and $0.3 \mu \mathrm{l}$ of either ibotenic acid (Sigma, St. Louis, MO, USA; $10 \mu \mathrm{g} /$ $\mu \mathrm{l})$ or artificial cerebrospinal fluid was bilaterally infused over a 2-min period by a micro-infusion pump (PHD Programmable, Harvard Biosciences) using an injection cannula $(0.3 \mathrm{~mm} \varnothing)$ aimed at the ventral hippocampal formation (AP $-3.0 \mathrm{~mm}$, ML $\pm 3.5 \mathrm{~mm}$ and VD $-5.0 \mathrm{~mm}$ relative to bregma). Following infusion, the skin overlying the skull was sutured and the animals allowed to recover on a heating pad before being returned to their mother. Eighteen days after surgery (i.e. PND25) rats were weaned and housed four per cage. Behavioral testings occurred between 9 a.m. and 4 p.m., and was initiated after puberty at PND70. 


\section{Prepulse Inhibition (PPI) of Startle Reflex}

The apparatus consisted of eight startle chambers (SRLAB, San Diego Instruments, CA, USA), containing a transparent Plexiglas tube (diameter $8.2 \mathrm{~cm}$, length 20 $\mathrm{cm}$ ) mounted on a Plexiglas frame within a ventilated enclosure. Acoustic noise bursts were presented via a speaker mounted $24 \mathrm{~cm}$ above the tube. Throughout the session a background noise level of $68 \mathrm{~dB}$ was maintained. A piezoelectric accelerometer mounted below the frame detected and transduced motion within the tube. Startle amplitudes were defined as the average of $1001 \mathrm{~ms}$ stabilimeter readings collected from stimulus onset. Rats were run in squads of eight. Each rat was put into the PPI chamber for a 5-min acclimatization period with a $68 \mathrm{~dB}$ background noise. Following this period, 10 startle pulses $(120 \mathrm{~dB}, 40 \mathrm{msec}$ duration) were presented with an average inter-trial interval of $15 \mathrm{~s}$. Then, no stimulus (background noise, $68 \mathrm{~dB}$ ), prepulses alone $(72,76,80$ or $84 \mathrm{~dB}, 20 \mathrm{msec}$ duration), startle pulses alone, and prepulses followed $80 \mathrm{msec}$ later by startle pulses were presented six times randomly distributed over the next $20 \mathrm{~min}$. The percentage of PPI induced by each prepulse intensity was calculated as: $100((\mathrm{SP}-\mathrm{SPP}) / \mathrm{SP})$ with SP being the average startle amplitude following the startle pulses and SPP being the average startle response following the combination of a certain prepulse and the startle pulse.

\section{Drugs}

Clozapine (Novartis, Switzerland) and olanzapine (synthesized at Roche) were dissolved in $0.1 \mathrm{~N} \mathrm{HCl}$ in $\mathrm{NaCl}$ $0.9 \%$ solution and neutralized to $\mathrm{pH} 6-7$ with $0.1 \mathrm{~N}$ $\mathrm{NaOH}$. Haloperidol (Janssen-Cilag) was prepared from $5 \mathrm{mg}$ ampoules containing the drug in $1 \mathrm{ml}$ solvent and diluted with $\mathrm{NaCl} 0.9 \%$ solution to obtain the required concentrations. Risperidone (Sigma) was dissolved in Tween $80(0.3 \%)$ in $\mathrm{NaCl} 0.9 \%$. Solvent injections consisted of $\mathrm{NaCl} 0.9 \%$ injections in haloperidol, clozapine and olanzapine experiments and of Tween $80(0.3 \%)$ in $\mathrm{NaCl} 0.9 \%$ in risperidone experiments. All drugs were administered in a volume of $5 \mathrm{ml} / \mathrm{kg}$ intraperitoneally 30 min prior testing. In each experiment, drugs were administered using a pseudo-randomized design over two or three treatment cycles with a minimum period of two weeks between two cycles. For haloperidol, clozapine and olanzapine experiments, rats were tested twice in PPI paradigm, whereas for the risperidone experiment they were tested three times.

\section{Rating of Lesion Size (According to Sams-Dodd et al. 1997)}

At the completion of behavioral evaluation, rats were killed by decapitation. Brains were rapidly removed and after fixation in formalin solution $(10 \%$ in $\mathrm{NaCl})$, $40-\mu \mathrm{m}$ sections were sliced with a freezing cryostat. The sections through the lesioned area were mounted and stained with cresyl violet. The extent of the lesion on each side of the brain was rated as follows: 0- no discernible cell loss in the hippocampal formation, 1- small, 2- medium, 3- large area of cell loss within the ventral hippocampal formation. Scores for both sides were added to yield a total score ranging from 0 to 6 .

\section{Analysis of Data}

PPI data were analyzed using a 3-factor ANOVA (lesion status $\times$ antipsychotic dose $\times$ prepulse intensity) with repeated measurements on factor prepulse intensity, followed when appropriate by separate 2-factor ANOVA or by the Fisher's PLSD post-hoc test. Startle amplitude data were analyzed by a 2-factor ANOVA (lesion status $\times$ antipsychotic dose) followed when appropriate by post-hoc comparisons (Fisher's PLSD test).

\section{RESULTS}

\section{Histology}

Subjects with only unilateral or extrahippocampal damage were discarded from the study (haloperidol experiment: 12 rats, clozapine experiment: 11 rats, olanzapine experiment: 5 rats and risperidone experiment: 2 rats). Neonatally-lesioned rats evaluated in PPI experiments exhibited mean lesion score between $3.51 \pm 0.15$ and $3.69 \pm 0.16$ indicating that the cell loss was restricted to the ventral part of the hippocampus (Figure 1). Some animals exhibited cavitation around the site of injection. In control rats that had been injected with artificial cerebrospinal fluid, the hippocampus was morphologically intact (lesion score 0 ).

\section{PPI}

Haloperidol. Neonatal ventral hippocampal lesions induced significant PPI deficits, and these effects were not opposed by haloperidol (Figure 2). A 3-way ANOVA of PPI revealed a significant effect of the lesion $\left(\mathrm{F}_{1,135}=41.4, p<.0001\right)$, no significant overall effect of haloperidol $\left(\mathrm{F}_{3,135}=0.7, \mathrm{NS}\right)$ and a significant interaction lesion $\times$ haloperidol $\left(\mathrm{F}_{3,135}=2.7, p<.05\right)$ indicating that haloperidol had different effects in sham and lesioned animals. Post-hoc comparisons revealed that haloperidol $1 \mathrm{mg} / \mathrm{kg}$ induced a significant reduction of PPI $(p<.01)$ in sham animals but not in NVH lesioned rats. The overall analysis also showed a significant effect of prepulse intensity $\left(\mathrm{F}_{3,405}=253.9, p<.0001\right)$, a significant interaction of lesion $\times$ prepulse intensity $\left(\mathrm{F}_{3,402}=8.2, p<.0001\right)$, and no other 2- or 3-way interactions. Separate ANOVAs were performed for each prepulse intensity tested and revealed a lesion-induced 
A

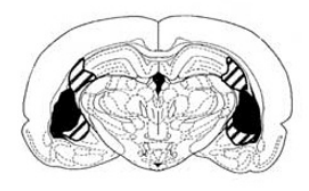

Bregma $-4.3 \mathrm{~mm}$

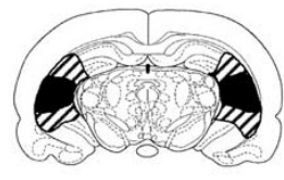

Bregma $-5.3 \mathrm{~mm}$

B

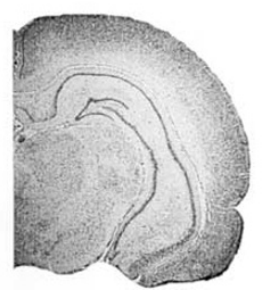

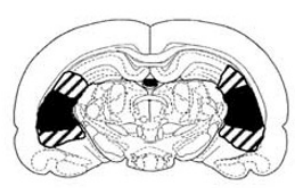

Bregma $-4.8 \mathrm{~mm}$

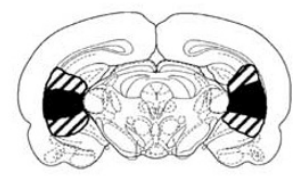

Bregma $-5.8 \mathrm{~mm}$

C

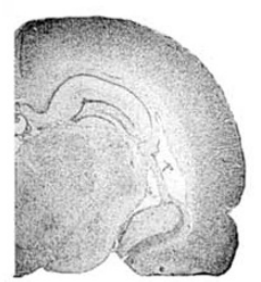

Figure 1. Lesion boundaries in the ventral hippocampus of adult rats infused bilaterally with ibotenic acid at postnatal day 7. (A) A schematic drawing of the ventral hippocampus with boundaries of the largest (stripes) and smallest (black) lesions. Representative photomicrographs of Cresyl violetstained coronal section through the brains of adult rats that had received sham (B) or neonatal (C) lesions of the ventral hippocampus.

decrease of PPI at each of the four prepulse intensities $(p<.0001)$. These ANOVAs also revealed a significant lesion $\times$ haloperidol interaction at $80 \mathrm{~dB}(p<.05)$ and a strong trend toward interaction at 76 and $84 \mathrm{~dB}(p=$ .066 and $p=.064$ respectively). Post-hoc comparisons revealed that haloperidol $1 \mathrm{mg} / \mathrm{kg}$ decreased PPI at 76, 80 and $84 \mathrm{~dB}$ in sham animals $(p<.05, p<.01$ and $p<$ .05 respectively) but not in lesioned rats.

Clozapine. Here also, neonatal ventral hippocampal lesions induced significant PPI deficits, and these effects were opposed by clozapine (Figure 3). A 3-way ANOVA of PPI revealed a significant effect of the lesion $\left(\mathrm{F}_{1,134}=16.4, p<.0001\right)$, a significant effect of clozapine $\left(\mathrm{F}_{3,134}=4.2, p<.01\right)$ and a significant interaction lesion $\times$ clozapine $\left(\mathrm{F}_{3,134}=4.2, p<.01\right)$ indicating that clozapine had different effects in sham and lesioned animals. Post-hoc comparisons revealed that PPI was significantly decreased in sham animals pretreated with 5 $\mathrm{mg} / \mathrm{kg}$ of clozapine $(p<.05)$. In contrast, in NVH lesioned rats, PPI was significantly greater in rats pretreated with 12 and $20 \mathrm{mg} / \mathrm{kg}$ of clozapine as compared with rats pretreated with solvent (both $p<.01$ ). The

overall analysis also revealed a significant effect of prepulse intensity $\left(\mathrm{F}_{3,402}=206.9, p<.0001\right)$, a significant interaction of lesion $\times$ prepulse intensity $\left(\mathrm{F}_{3,402}=\right.$ $10.3, p<.0001$ ) and no other 2- or 3-way interactions. Separate ANOVAs were performed for each prepulse intensity tested and revealed a lesion-induced decrease of PPI at each of the four prepulse intensities $(p<.0001$, $p<.001, p<.05$ and $p<.01$ respectively). At 76, 80 and $84 \mathrm{~dB}$, these ANOVAs also revealed a significant effect of clozapine $(p<.05, p<.01$ and $p<.001$ respectively) and a significant lesion $\times$ clozapine interaction $(p<.05$, $p<.01$ and $p<.05$ respectively). Post-hoc comparisons showed that clozapine dose-dependently and fully reversed PPI deficits induced by $\mathrm{NVH}$ lesions at 76, 80 and $84 \mathrm{~dB}$. Moreover, the post-hoc test revealed that clozapine $5 \mathrm{mg} / \mathrm{kg}$ also partially reversed this deficit at $80 \mathrm{~dB}$. In sham operated animals, clozapine $5 \mathrm{mg} / \mathrm{kg}$ reduced significantly PPI at 80 and $84 \mathrm{~dB}(p<.01$ and $p<$ .05 respectively).

Olanzapine. PPI deficits induced by neonatal ventral hippocampal lesions were also opposed by olanzapine treatment (Figure 4). Indeed, a 3-way ANOVA of PPI revealed a significant effect of the lesion $\left(\mathrm{F}_{1,155}=25, p<\right.$ $.0001)$, no overall effect of olanzapine $\left(\mathrm{F}_{3,155}=0.9\right.$, NS) and a significant interaction lesion $\times$ olanzapine $\left(\mathrm{F}_{3,155}\right.$ $=3.8, p<.05$ ) indicating that olanzapine had different effects in sham and lesioned animals. Post-hoc comparisons revealed that olanzapine induced a reduction of PPI at $10 \mathrm{mg} / \mathrm{kg}$ in sham animals $(p<.05)$. In contrast, in lesioned rats, PPI was significantly greater in rats pretreated with $3 \mathrm{mg} / \mathrm{kg}$ of olanzapine than in rats pretreated with solvent $(p<.05)$. The overall analysis also showed a significant effect of prepulse intensity $\left(\mathrm{F}_{3,465}=\right.$ 234.5, $p<.0001$ ), a significant interaction of lesion $\times$ prepulse intensity $\left(\mathrm{F}_{3,465}=11.7, p<.0001\right)$, a significant lesion $\times$ olanzapine interaction $\left(\mathrm{F}_{3,465}=2.3, p<.05\right)$ and no 3-way interaction. Separate ANOVAs were performed for each prepulse intensity tested and revealed a lesion-induced decrease of PPI at each of the four prepulse intensities $(p<.0001, p<.0001, p<.01$ and $p<.001$ respectively). These ANOVAs also revealed a significant lesion $\times$ olanzapine interaction at $76 \mathrm{~dB}(p<$ $.01)$ and a strong trend toward interaction at 72 and 84 $\mathrm{dB}(p=.057$ and $p=.066$ respectively). Post-hoc comparisons revealed that olanzapine $3 \mathrm{mg} / \mathrm{kg}$ fully reversed PPI deficits induced by $\mathrm{NVH}$ lesions at 72 and $80 \mathrm{~dB}$. Olanzapine 3 and $10 \mathrm{mg} / \mathrm{kg}$ also partially reversed this deficit at $76 \mathrm{~dB}$. In sham operated animals, olanzapine 3 and $10 \mathrm{mg} / \mathrm{kg}$ reduced significantly PPI at $76 \mathrm{db}(p<.05)$.

Risperidone. Here again, neonatal ventral hippocampal lesions induced significant PPI deficits, and these effects were opposed by risperidone (Figure 5). A 3-way ANOVA of PPI revealed a significant effect of the lesion $\left(\mathrm{F}_{1,163}=32.5, p<.0001\right)$, no overall effect of risperidone $\left(\mathrm{F}_{3,163}=3.8, \mathrm{NS}\right)$ and a significant interaction lesion $\times$ 


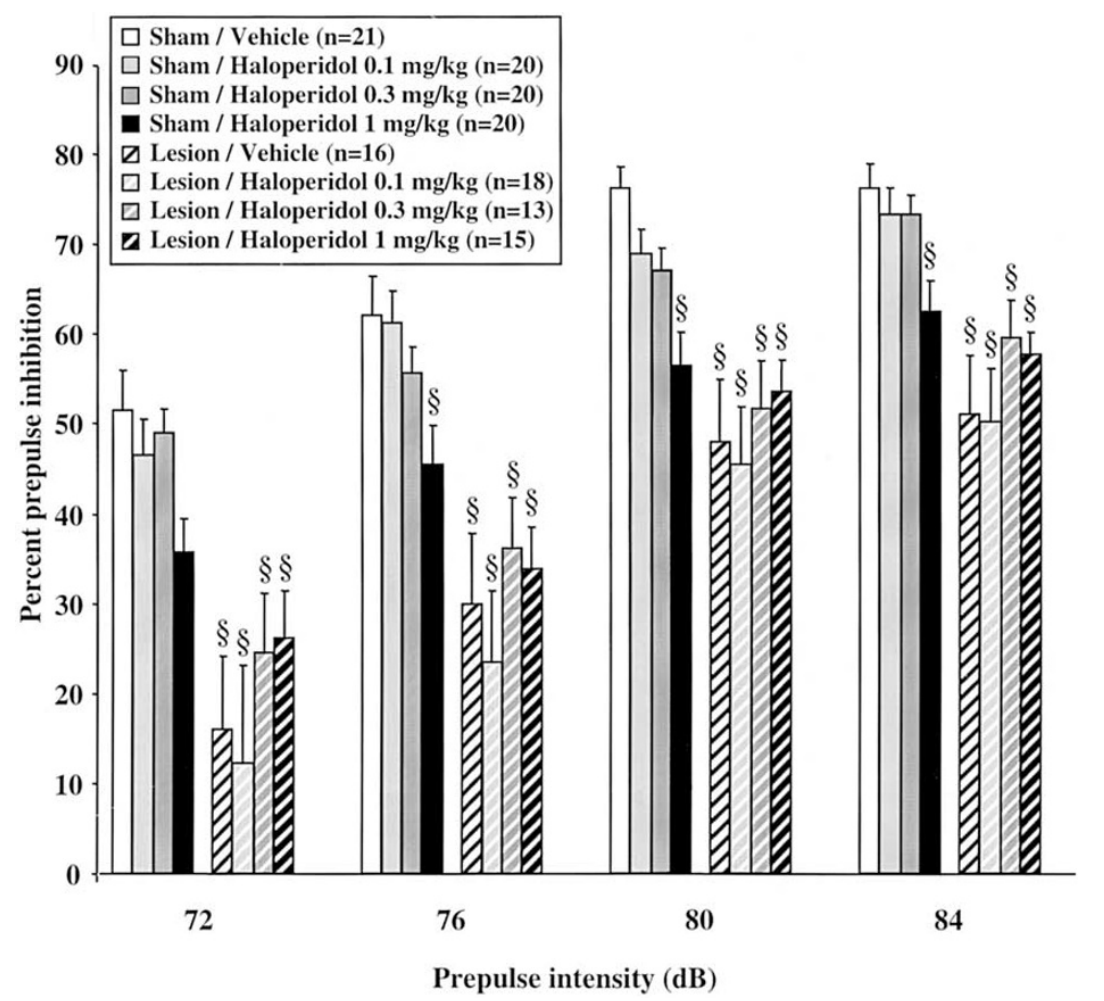

Figure 2. Effects of haloperidol on neonatal ventral hippocampal lesion-induced deficits in prepulse inhibition of startle reflex. A dose response study using vehicle, 0.1, 0.3 or $1 \mathrm{mg} / \mathrm{kg}$ of haloperidol injected i.p. $30 \mathrm{~min}$ before testing was performed. ${ }^{\S} p<$ .05 at least compared with Sham/Vehicle group.

risperidone $\left(\mathrm{F}_{3,163}=3.8, p<.05\right)$ indicating that risperidone had different effects in sham and lesioned animals. Post-hoc comparisons revealed no significant effect of risperidone on PPI in sham animals. In contrast, in NVH lesioned rats, a post-hoc test revealed that PPI was significantly greater in rats pretreated with $0.1,0.3$ and $1 \mathrm{mg} / \mathrm{kg}$ of risperidone than in rats pretreated with solvent $(p<.05, p<.05$ and $p<.001$ respectively). The overall analysis also revealed a significant effect of prepulse intensity $\left(\mathrm{F}_{3,489}=293.1, p<\right.$ .0001), a significant interaction of prepulse intensity $\times$ risperidone $\left(\mathrm{F}_{9,489}=1.9, p<.05\right)$ and no other 2 - or 3-way interactions. Separate ANOVAs were performed for each prepulse intensity tested and revealed a lesion-induced decrease of PPI at each of the four prepulse intensities $(p<.0001)$. These ANOVAs also revealed a significant effect of risperidone 80 and 84 $\mathrm{dB}(p<.05$ and $p<.01$ respectively) and a significant lesion $\times$ risperidone interaction at the four prepulse intensities tested $(p<.05, p<.01, p<.05$ and $p<.05$ respectively). Post-hoc comparisons showed that risperidone $(0.1 \mathrm{mg} / \mathrm{kg})$ partially reversed PPI deficits induced by NVH lesions at $72 \mathrm{~dB}$. PPI deficits were significantly reversed by risperidone 0.1 and $1 \mathrm{mg} / \mathrm{kg}$ at $76 \mathrm{~dB}$ (strong tendency at $0.3 \mathrm{mg} / \mathrm{kg}: p=.068$ ). These deficits were dose-dependently and fully reversed by risperidone at 80 and $84 \mathrm{~dB}(0.3$ and $1 \mathrm{mg} /$ $\mathrm{kg}$, strong tendency at $0.1 \mathrm{mg} / \mathrm{kg}(p=.068))$. Finally, in sham operated animals, risperidone $0.1 \mathrm{mg} / \mathrm{kg}$ significantly reduced PPI at 72 and $76 \mathrm{~dB}$.

\section{Startle Amplitude}

Drug effects on startle amplitude (pulse alone) are seen in Figure 6.

In clozapine, olanzapine and risperidone experiments (Figure 6, panels B, C and D respectively), we replicated the previous finding that lesion has no effect on startle amplitude (Lipska et al. 1995b; Le Pen et al. 2000) but surprisingly, a significant overall lesion effect was found in the haloperidol experiment $\left(\mathrm{F}_{1,135}=7.1, p<.01\right)$ (Figure 6, panel A). However, post-hoc comparisons revealed a significant decrease $(p<.05)$ of startle amplitude in NVHlesioned rats only at the $0.1 \mathrm{mg} / \mathrm{kg}$ dose of haloperidol.

Moreover, in haloperidol, clozapine, olanzapine and risperidone experiments (Figure 6, panels A, B, C, and D respectively), the amplitude of the startle response decreased significantly with increasing antipsychotic doses $\left(\mathrm{F}_{3,135}=12, p<.0001 ; \mathrm{F}_{3,134}=23.7, p<.0001 ; \mathrm{F}_{3,157}\right.$ $=12.3, p<.0001$ and $\mathrm{F}_{3,157}=12.3, p<.0001$ respectively), but no significant lesion $\times$ antipsychotic interaction could be detected. Post-hoc comparisons show that, in both sham and lesioned animals, haloperidol, clozapine and risperidone induced a decrease of startle amplitude at the three doses tested whereas with olanzapine this reduction is only observed at 3 and $10 \mathrm{mg} / \mathrm{kg}$.

\section{DISCUSSION}

In good agreement with previous reports (Lipska et al. 1995b; Le Pen et al. 2000), we show in this study that 


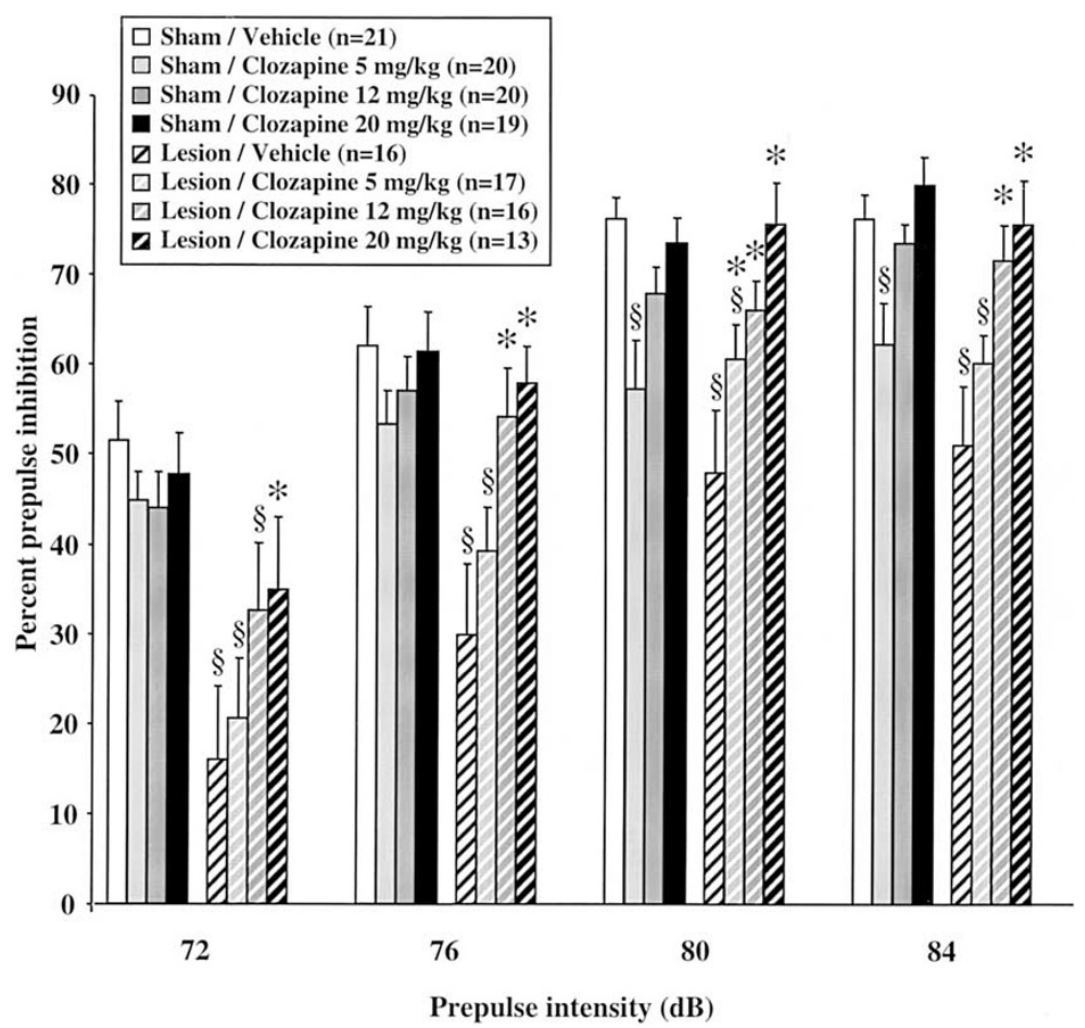

Figure 3. Effects of clozapine on neonatal ventral hippocampal lesion-induced deficits in prepulse inhibition of startle reflex. A dose response study using vehicle, 5,12 or $20 \mathrm{mg} / \mathrm{kg}$ of clozapine injected i.p. $30 \mathrm{~min}$ before testing was performed. ${ }^{\S} p<.05$ at least compared with Sham/Vehicle group. ${ }^{*} p<.05$ at least compared with Lesion / Vehicle group.

$\mathrm{NVH}$ lesions induced deficits in sensorimotor gating using PPI of startle paradigm. These experiments are also the first to investigate the capacity of antipsychotics to reverse the PPI deficits observed in the NVHlesioned rats.

We show that NVH lesions-induced PPI deficits are fully or partially reversed by atypical antipsychotics such as clozapine, olanzapine and risperidone but not by haloperidol, a typical antipsychotic. These results partly replicate previous data obtained in other neurodevelopmental animal models of schizophrenia. Indeed, it has been shown that clozapine, risperidone, quetiapine or olanzapine were able to reverse PPI deficits induced by isolation rearing (Geyer et al. 1993; Varty and Higgins 1995; Bakshi et al. 1998; Bakshi and Geyer 1999) and quetiapine reversed those induced by maternal deprivation (Ellenbroek et al. 1998). In contrast to our results, in these studies, PPI deficits were also antagonized by haloperidol.

However, our results are also in good agreement with clinical data obtained in schizophrenic patients. Indeed, disruptions of sensorimotor gating processes are commonly shown in schizophrenic patients using PPI of the startle reflex (Perry and Braff 1994; Kumari et al. 2000; Parwani et al. 2000). These PPI deficits seem to be best treated by atypical antipsychotics, as clozapine normalized information processing functions in clinically-stable psychotic patients (Kumari et al. 1999) whereas this was not the case in such patients treated with typical neuroleptics (Braff et al. 1978; Braff and
Geyer 1990; Braff et al. 1992; Bolino et al. 1992; Grillon et al. 1992).

Another parallel between our results and data obtained in humans lies in the fact that, in normal volunteers, haloperidol on its own reduced prepulse inhibition of the startle reflex (Abduljawad et al. 1998; Kumari et al. 1998). Indeed, in our studies, in shamoperated animals, reduction of PPI has been observed after a high dose of haloperidol $(1 \mathrm{mg} / \mathrm{kg})$ at three of the prepulse intensities tested. This reduction was also observed after olanzapine ( 3 and $10 \mathrm{mg} / \mathrm{kg}$ ), clozapine $(5 \mathrm{mg} / \mathrm{kg})$ and risperidone $(0.1 \mathrm{mg} / \mathrm{kg})$. These PPI reductions could be explained in part by antipsychoticinduced reductions in startle amplitudes and associated floor effects. However, this is unlikely to be the case since no reductions of PPI have been noticed with high doses of clozapine or risperidone which drastically affected startle.

In good agreement with the literature (Davis and Aghajanian 1976; Swerdlow and Geyer 1993; Varty and Higgins 1995; Schwarzkopf et al. 1996; Bakshi et al. 1998), we also showed that haloperidol, clozapine, olanzapine and risperidone dose-dependently reduced the startle in sham-operated animals, but also in NVH-lesioned rats. Thus, it is worth noting that the inability of haloperidol to reverse PPI deficits observed in NVH-lesioned rats is unlikely to be simply a consequence of its reduction of startle, as: (1) such a reversal is obtained with doses of clozapine, olanzapine or risperidone which by themselves inhibit startle; 


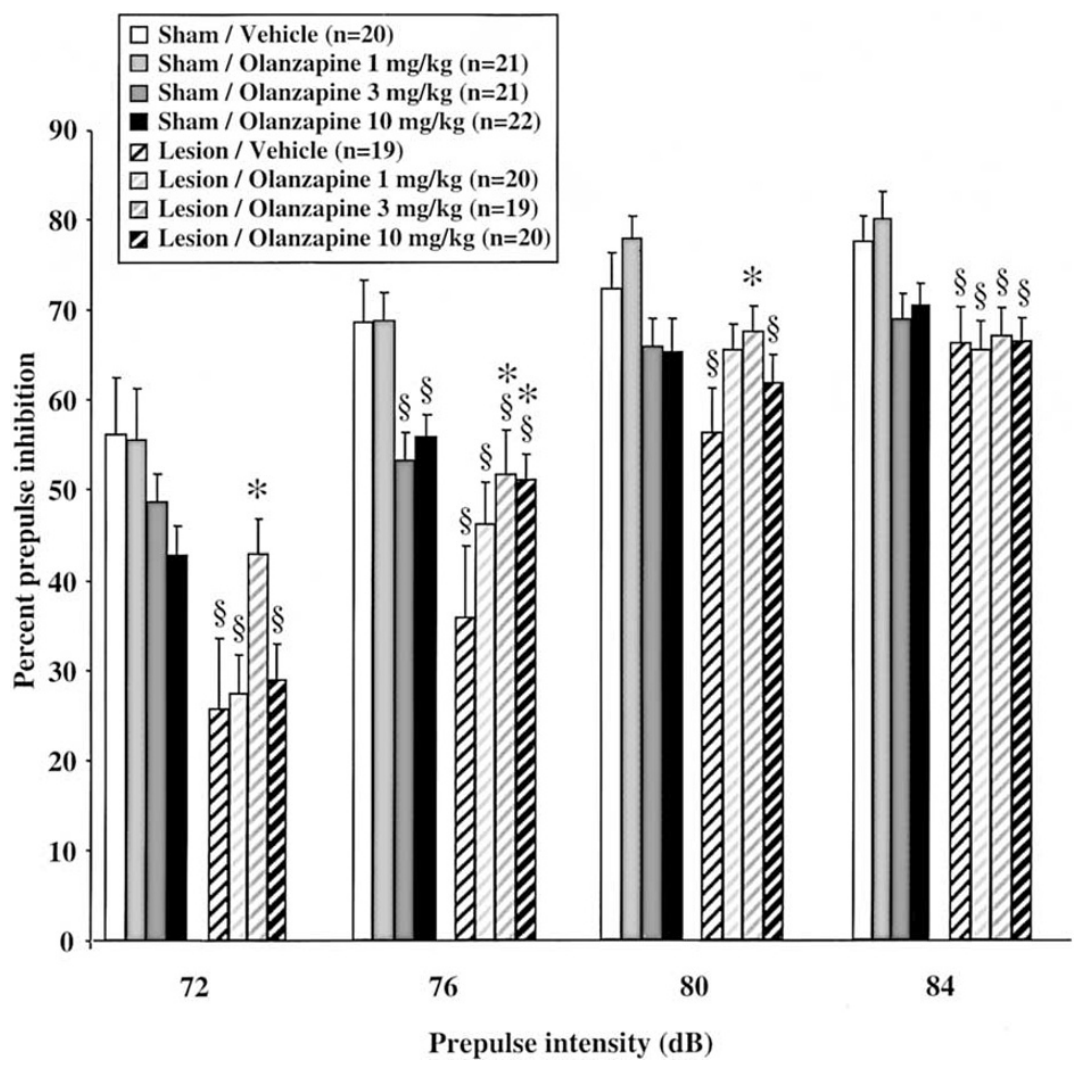

Figure 4. Effects of olanzapine on neonatal ventral hippocampal lesions-induced deficits in prepulse inhibition of startle reflex. A dose response study using vehicle, 1,3 or $10 \mathrm{mg} / \mathrm{kg}$ of olanzapine injected i.p. 30 min before testing was performed. ${ }^{\S} p<$ .05 at least compared with Sham/Vehicle group. ${ }^{*} p<.05$ at least compared with Lesion/Vehicle group. and (2) antipsychotics appeared to reduce startle similarly in both sham and lesioned rats while only altering PPI in the lesioned rats. Thus, as previously stated, there is no consistent relationship between the startle amplitude value and the effectiveness of a given antipsychotic to restore PPI deficits (Schwarzkopf et al. 1992; Varty and Higgins 1995; Swerdlow et al. 1996).

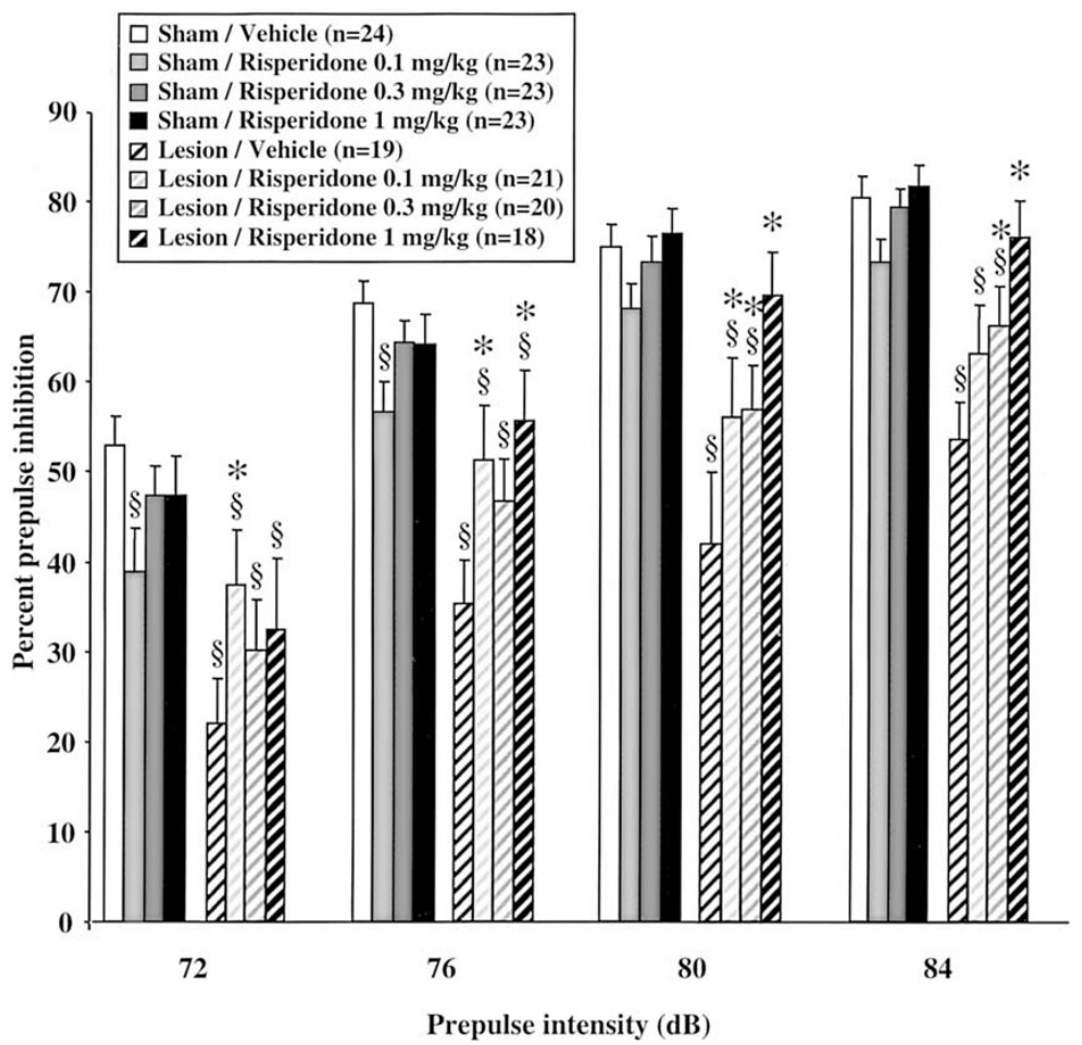

Figure 5. Effects of risperidone on neonatal ventral hippocampal lesion-induced deficits in prepulse inhibition of startle reflex. A dose response study using vehicle, 0.1 , 0.3 or $1 \mathrm{mg} / \mathrm{kg}$ of risperidone injected i.p. $30 \mathrm{~min}$ before testing was performed. ${ }^{\S} p<$ .05 at least compared with Sham/Vehicle group. ${ }^{*} p<.05$ at least compared with Lesion/Vehicle group. 


\begin{tabular}{|l|l|}
\hline$\square$ Sham / Vehicle $\square$ Lesion / Vehicle \\
$\square$ Sham / Haloperidol $0.1 \mathrm{mg} / \mathrm{kg} \square$ Lesion / Haloperidol $0.1 \mathrm{mg} / \mathrm{kg}$ \\
$\square$ Sham / Haloperidol $0.3 \mathrm{mg} / \mathrm{kg} \square$ Lesion / Haloperidol $0.3 \mathrm{mg} / \mathrm{kg}$ \\
$\square$ Sham / Haloperidol $1 \mathrm{mg} / \mathrm{kg} \square$ Lesion / Haloperidol $1 \mathrm{mg} / \mathrm{kg}$
\end{tabular}
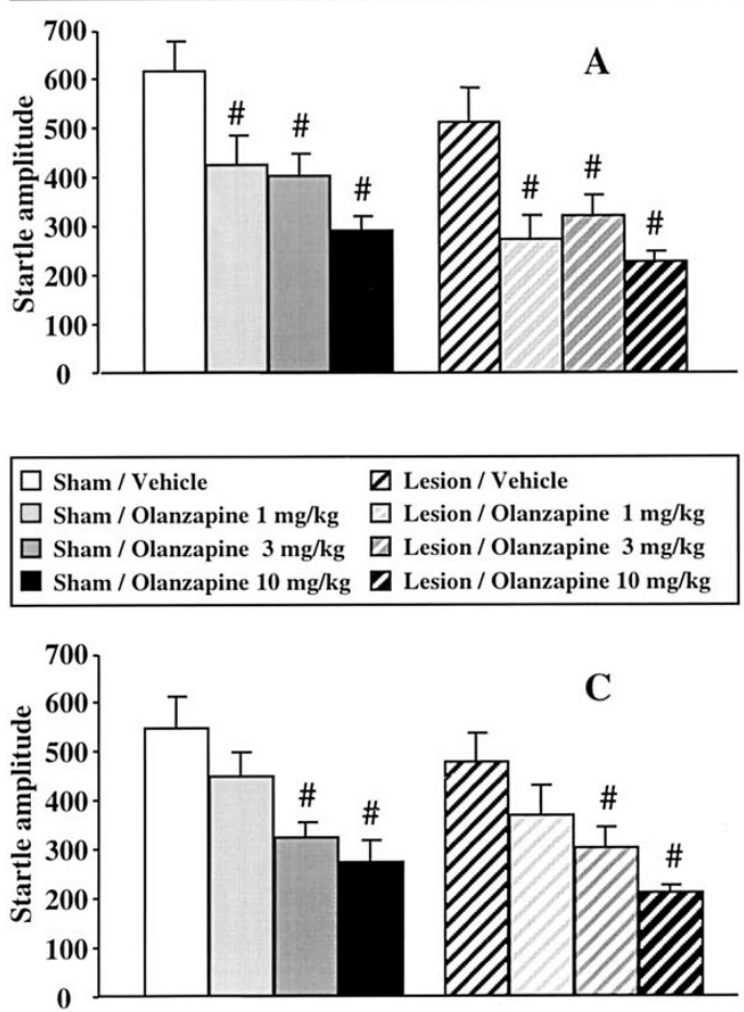
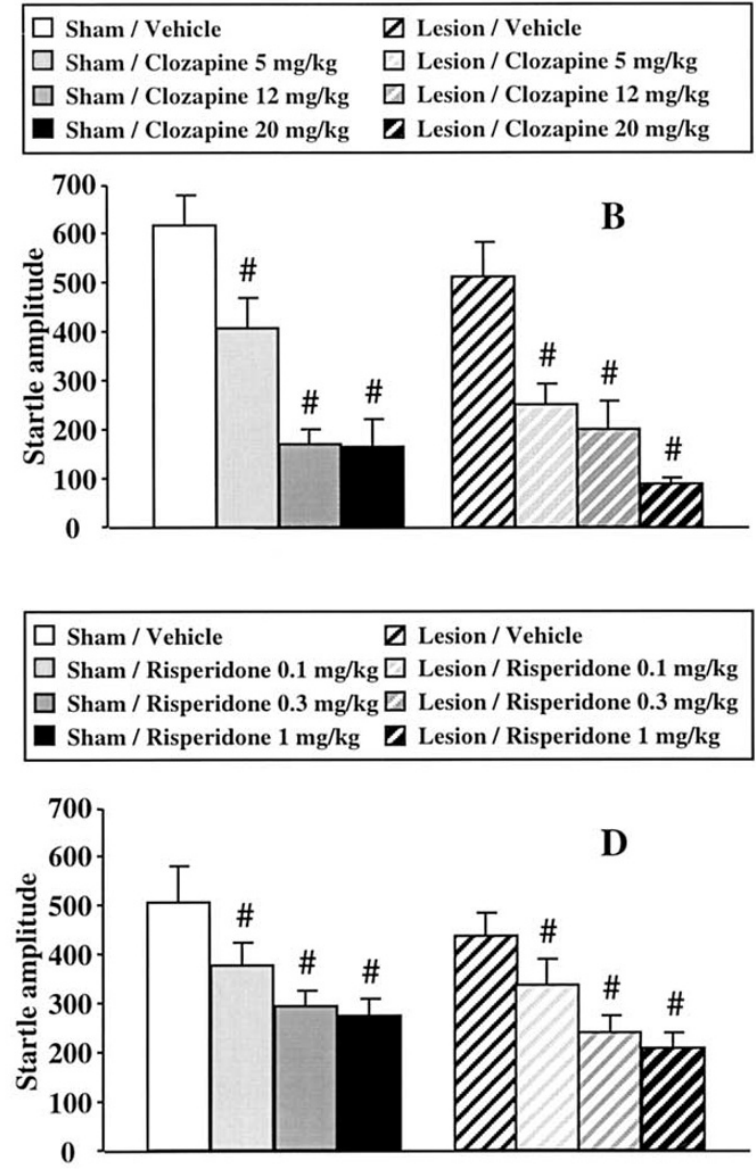

Figure 6. Effects of haloperidol (A), clozapine (B), olanzapine (C) and risperidone (D) on startle amplitude in sham-operated and neonatal ventral hippocampal lesioned rats. $\# p<.05$ at least compared with respective control group.

We showed that atypical antipsychotics, but not a typical antipsychotic, haloperidol, are able to reverse PPI deficits observed in NVH-lesioned rats. This suggests that these deficits might be particularly sensitive to some critical properties linked to the "atypicality" of those antipsychotic drugs. Interestingly, intra-ventral hippocampus or subiculum infusions of NMDA induce disruptions of PPI which are antagonized by a systemic administration of clozapine but not by haloperidol (Wan et al. 1998; Zhang et al. 1999). Thus, to normalize PPI deficits, atypical antipsychotics such as clozapine, olanzapine and risperidone probably interact with brain systems affected by NVH lesions through their action on receptors other than DA receptors. In contrast to haloperidol, atypical antipsychotics also interact, among others, with 5HT2A, $\alpha 2$ adrenergic, muscarinic and histaminergic receptors. All of them could play an important role for the unique action of atypical antipsychotics in our experiments. Thus, for example, it would be interesting to test the capacity of M100907 and atipamezole, selective antagonists of 5-HT2A and $\alpha 2$ adrenergic receptors respectively, to reverse PPI deficits observed in NVH lesioned rats.
Atypical antipsychotics were also found to be more potent than typical ones to reverse behavioral changes induced by GLU receptor antagonists. Indeed, clozapine, olanzapine, or risperidone, in contrast to haloperidol, attenuated PCP-induced reduction of PPI in rats (Keith et al. 1991; Bakshi et al. 1994; Bakshi and Geyer 1995; Varty and Higgins 1995; Swerdlow et al. 1996; Yamada et al. 1999). Yamada and colleagues have shown that the ability of drugs to reverse PCP-induced PPI disruption is correlated to their affinity for 5HT2A, not D2 receptors (Yamada et al. 1999) consistent with the hypothesis that serotonin (via 5HT2A receptor) and glutamate could interact in modulating PPI (Varty et al. 1999). These results suggest that NVH-induced PPI deficits could result from a dysfunctioning of the glutamate system which could be antagonized more potently by atypical antipsychotics. This hypothesis is also supported by various data obtained in NVHlesioned rats. Indeed, in the hippocampal formation as well as in the frontal cortex of NVH lesioned rats, a hypofunctioning of the glutamatergic system was shown by measuring ex vivo amino acid release from tissue slices (Schroeder et al. 1999). Moreover, it has been 
shown that $\mathrm{NVH}$-lesioned rats are hypersensitive to GLU receptor antagonists MK-801 (Lillrank et al. 1996; Al-amin et al. 2000, 2001) and to PCP (Hori et al. 2000; Kato et al. 2000).

In conclusion, the present study shows that the NVH lesion model is endowed with a fair predictive validity as, in lesioned animals like in schizophrenic patients, PPI deficits are reversed by atypical antipsychotics but not by the typical neuroleptic haloperidol.

\section{REFERENCES}

Abduljawad KA, Langley RW, Bradshaw CM, Szabadi E (1998): Effects of bromocriptine and haloperidol on prepulse inhibition of the acoustic startle response in man. J Psychopharmacol 12:239-245

Al-Amin HA, Weinberger DR, Lipska BK (2000): Exaggerated MK-801-induced motor hyperactivity in rats with the neonatal lesion of the ventral hippocampus. Behav Pharmacol 11:269-278

Al-Amin HA, Weinberger DR, Lipska BK (2001): Delayed onset of enhanced MK-801-induced motor hyperactivity after neonatal lesions of the rat ventral hippocampus. Biol Psychiatry 49:528-539

Angrist B, van Kammen DP (1984): CNS stimulants as a tool to study schizophrenia. Trends Neurosci 7:388-390

Bakshi VP, Swerdlow NR, Geyer MA (1994): Clozapine antagonizes phencyclidine-induced deficits in sensorimotor gating of the startle response. J Pharmacol Exp Ther 271:787-794

Bakshi VP, Geyer MA (1995): Antagonism of phencyclidineinduced deficits in prepulse inhibition by the putative atypical antipsychotic olanzapine. Psychopharmacology 122:198-201

Bakshi VP, Swerdlow NR, Braff DL, Geyer MA (1998): Reversal of isolation rearing-induced deficits in prepulse inhibition by seroquel and olanzapine. Biol Psychiatry 43:436-445

Bakshi VP, Geyer MA (1999): Ontogeny of isolation rearinginduced deficits in sensorimotor gating in rats. Physiol Behav 67:385-392

Becker A, Grecksch G, Berstein H-G, Höllt V, Bogerts B (1999): Social behaviour in rats lesioned with ibotenic acid in the hippocampus: quantitative and qualitative analysis. Psychopharmacology 144:333-338

Becker A, Grecksch G (2000): Social memory is impaired in neonatally ibotenic acid lesioned rats. Behav Brain Res 109:137-140

Becker A, Grecksch G, Peters B (2000): Social behaviour in rats neonatally lesioned with ibotenic acid: effects of haloperidol and clozapine. Behav Pharmacol 11:333

Black MD, Lister S, Hitchcock JM, Van Giersbergen P, Sorensen SM (1998): Neonatal hippocampal lesion model of schizophrenia in rats: sex differences and persistence of effects into maturity. Drug Dev Res 43:206213

Bolino F, Manna V, Di Cicco L, Di Michele V, Daneluzzo E, Rossi A, Casacchia M (1992): Startle reflex habituation in functional psychoses: a controlled study. Neurosci Lett 145:126-128

Bolino F, Di Michele V, Di Cicco L, Manna V, Daneluzzo E, Casacchia M (1994): Sensorimotor gating and habituation evoked by electro-cutaneous stimulation in schizophrenia. Biol Psychiatry 36:670-679

Braff D, Stone C, Callaway E, Geyer M, Glick I, Bali L (1978): Prestimulus effects on human startle reflex in normals and schizophrenics. Psychophysiology 15:339-343

Braff DL, Geyer MA (1990): Sensorimotor gating and schizophrenia. Human and animal model studies. Arch Gen Psychiatry 47:181-188

Braff DL, Grillon C, Geyer MA (1992): Gating and habituation of the startle reflex in schizophrenic patients. Arch Gen Psychiatry 49:206-215

Braff DL (1993): Information processing and attention dysfunctions in schizophrenia. Schizophr Bull 19:233-259

Brake WG, Sullivan RM, Flores G, Srivastava LK, Gratton A (1999): Neonatal ventral hippocampal lesions attenuate the nucleus accumbens dopamine response to stress: an electrochemical study in the adult rat. Brain Res 831: 25-32

Chambers RA, Moore JM, McEvoy JP, Levin ED (1996): Cognitive effects of neonatal hippocampal lesions in rat model of schizophrenia. Neuropsychopharmacology 15:587-594

Davis M, Aghajanian GK (1976): Effects of apomorphine and haloperidol on the acoustic startle response in rats. Psychopharmacology 47:217-223

Duncan GE, Sheitman BB, Lieberman JA (1999): An integrated view of pathophysiological models of schizophrenia. Brain Res Rev 29:250-264

Ellenbroek BA, Cools AR (1990): Animal models with construct validity for schizophrenia. Behav Pharmacol 1:469-490

Ellenbroek BA, Cools AR (1998): The neurodevelopmental hypothesis of schizophrenia: Clinical evidence and animal models. Neurosci Res Communications 22:127-136

Ellenbroek BA, Van Den Kroonenberg PTJM, Cools AR (1998): The effects of an early stressful life event on sensorimotor gating in adult rats. Schizophrenia Res $30: 251-260$

Flores G, Barbeau D, Quirion R, Srivastava LK (1996): Decreased binding of dopamine D3 receptors in limbic subregions after neonatal bilateral lesion of rat hippocampus. J Neurosci 16:2020-2026

Geyer MA, Wilkinson LS, Humby T, Robbins TW (1993): Isolation rearing of rats produces a deficit in prepulse inhibition of acoustic startle similar to that in schizophrenia. 34:361-372

Grillon C, Ameli R, Charney DS, Krystal J, Braff D (1992): Startle gating deficits occur across prepulse intensities in schizophrenic patients. Biol Psychiatry 32:939-943

Hori T, Subramaniam S, Srivastava LK, Quirion R (2000): Behavioral and neurochemical alterations following repeated phencyclidine administration in rats with neonatal ventral hippocampal lesions. Neuropharmacology 39:2478-2491

Kato K, Shishido T, Ono M, Shishido K, Kobayashi M, Suzuki H, Nabeshima T, Furukawa H, Niwa S (2000): 
Effects of phencyclidine on behavior and extracellular levels of dopamine and its metabolites in neonatal ventral hippocampal damaged rats. Psychopharmacology 150:163-169

Keith VA, Mansbach RS, Geyer MA (1991): Failure of haloperidol to block the effects of phencyclidine and dizocilpine on prepulse inhibition of startle. Biol Psychiatry 30:557-566

Kumari V, Mulligan OF, Cotter PA, Poon L, Toone BK, Checkley SA, Gray JA (1998): Effects of single oral administration of haloperidol and d-amphetamine on prepulse inhibition of the acoustic startle reflex in healthy male volunteers. Behav Pharmacol. 9:567-576

Kumari V, Soni W, Sharma T (1999): Normalization of information processing deficits in schizophrenia with clozapine. Am J Psychiatry 156:1046-1051

Kumari V, Soni W, Mathew VM, Sharma T (2000): Prepulse inhibition of the startle response in men with schizophrenia: effects of age of onset of illness, symptoms, and medication. Arch Gen Psychiatry 57:609-614

Le Pen G, Grottick AJ, Higgins GA, Martin JR, Jenck F, Moreau J-L (2000): Spatial and associative learning deficits induced by neonatal excitotoxic hippocampal damage in rats: further evaluation of an animal model of schizophrenia. Behav Pharmacol 11:257-268

Lieberman JA, Kane JM, Alvir J (1987): Provocative tests with psychostimulant drugs in schizophrenia. Psychopharmacology 91:415-433

Lillrank SM, Lipska BK, Bachus SE, Wood GK, Weinberger DR (1996): Amphetamine-induced c-fos mRNA expression is altered in rats with neonatal ventral hippocampal damage. Synapse 23:292-301

Lipska BK, Weinberger DR (1993): Delayed effects of neonatal hippocampal damage on haloperidol-induced stereotypic behaviors in the rat. Develop Brain Res 75:213222

Lipska BK, Jaskiw GE, Weinberger DR (1993): Postpubertal emergence of hyperresponsiveness to stress and to amphetamine after neonatal excitotoxic hippocampal damage: a potential animal model of schizophrenia. Neuropsychopharmacology 9:67-75

Lipska BK, Weinberger MD (1994): Subchronic treatment with haloperidol and clozapine in rats with neonatal excitotoxic hippocampal damage. Neuropsychopharmacology 10:199-205

Lipska BK, Chrapusta SJ, Egan MF, Weinberger DR (1995a): Neonatal excitotoxic ventral hippocampal damage alters dopamine response to mild repeated stress and to chronic haloperidol. Synapse 20:125-130

Lipska BK, Swerdlow NR, Geyer MA, Jaskiw GE, Braff DL, Weinberger DR (1995b): Neonatal excitotoxic hippocampal damage in rats causes post-pubertal changes in prepulse inhibition of startle and its disruption by apomorphine. Psychopharmacology 122:35-43

Lipska BK, Weinberger DR (2000): To model a psychiatric disorder in animals: schizophrenia as a reality test. Neuropsychopharmacology 23:223-239

Meador-Woodruff JH, Healy DJ (2000): Glutamate receptor expression in schizophrenic brain. Brain Res Rev 31:288-294

Nuechterlein KH, Dawson ME, Green MF (1994): Informa- tion-processing abnormalities as neuropsychological vulnerability indicators for schizophrenia. Acta Psychiatr Scand (Suppl 384):71-79

Parwani A, Duncan EJ, Bartlett E, Madonick SH, Efferen TR, Rajan R, Sanfilipo M, Chappell PB, Chakravorty S, Gonzenbach S, Ko GN, Rotrosen JP (2000): Impaired prepulse inhibition of acoustic startle in schizophrenia. Biol Psychiatry 47:662-669

Perry W, Braff DL (1994): Information-processing deficits and thought disorder in schizophrenia. Am J Psychiatry 151:363-367

Sams-Dodd F, Lipska BK, Weinberger DR (1997): Neonatal lesions of the rat ventral hippocampus result in hyperlocomotion and deficits in social behaviour in adulthood. Psychopharmacology 132:303-310

Schroeder H, Grecksch G, Becker A, Bogerts B, Hoellt V (1999): Alterations of the dopaminergic and glutamatergic neurotransmission in adult rats with postnatal ibotenic acid hippocampal lesion. Psychopharmacology 145:61-66

Schwarzkopf SB, Mitra T, Bruno JP (1992): Sensory gating in rats depleted of dopamine as neonates: potential relevance to findings in schizophrenic patients. Biol Psychiatry 31:759-773

Schwarzkopf SB, Bruno JP, Mitra T, Ison JR (1996): Effects of haloperidol and SCH 23390 on acoustic startle in animals depleted of dopamine as neonates: implications for neuropsychiatric syndromes. Psychopharmacology 123:258-266

Swerdlow NR, Geyer MA (1993): Clozapine and haloperidol in an animal model of sensorimotor gating deficits in schizophrenia. Pharmacol Biochem Behav 44:741-744

Swerdlow NR, Braff DL, Taaid N, Geyer MA (1994): Assessing the validity of an animal model of deficient sensorimotor gating in schizophrenic patients. Arch Gen Psychiatry 51:139-154

Swerdlow NR, Bakshi V, Geyer MA (1996): Seroquel restores sensorimotor gating in phencyclidine-treated rats. J Pharmacol Exp Ther 279:1290-1299

Swerdlow NR, Geyer MA (1998): Using an animal model of deficient sensorimotor gating to study the pathophysiology and new treatments of schizophrenia. Schizophr Bull 24:285-301

Varty GB, Higgins GA (1995): Examination of drug-induced and isolation-induced disruptions of prepulse inhibition as models to screen antipsychotic drugs. Psychopharmacology 122:15-26

Varty GB, Bakshi VP, Geyer MA (1999): M100907, a serotonin 5-HT2A receptor antagonist and putative antipsychotic, blocks dizocilpine-induced prepulse inhibition deficits in Sprague-Dawley and Wistar rats. Neuropsychopharmacology 20:311-321

Wan FJ, Caine SB, Swerdlow NR (1998): The ventral subiculum modulation of prepulse inhibition is not mediated via dopamine D2 or nucleus accumbens non-NMDA glutamate receptor activity. Eur J Pharmacol 314:9-18

Weinberger DR (1986): The pathogenesis of schizophrenia: A neurodevelopmental theory. In Nasrallah HA, Weinberger DR (eds), The neurology of schizophrenia. Holland, Elsevier, pp 397-406

Yamada S, Harano M, Annoh N, Nakamura K, Tanaka M 
(1999): Involvement of serotonin $2 \mathrm{~A}$ receptors in phencyclidine-induced disruption of prepulse inhibition of the acoustic startle in rats. Biol Psychiatry 46: 832-838

Zhang W, Pouzet B, Jongen-Rolo AL, Weiner I, Feldon J
(1999): Disruption of prepulse inhibition following Nmethyl-D-aspartate infusion into the ventral hippocampus is antagonized by clozapine but not by haloperidol: a possible model for the screening of atypical antipsychotics. Neuroreport 10:2533-2538 